\section{Estudo \\ CoDebate}

em Cestão

Planejamento
Revista Estudo \& Debate, Lajeado, v. 24, n. 1, 2017. ISSN 1983-036X

DOI: http://dx.doi.org/10.22410/issn.1983-036X.v24i1a2017.1065

\title{
A CRISE ECONÔMICA MUNDIAL DE 2008 E O REFLEXO SOBRE AS INSTITUIÇÓES BANCÁRIAS BRASILEIRAS
}

\author{
Henrique Faverzani Drago ${ }^{1}$, Gilnei Luiz de Moura², Janaina Marchi ${ }^{3}$
}

\begin{abstract}
Resumo: Este artigo tem o objetivo de explicar por meio da literatura acadêmica como as instituiçóes bancárias brasileiras reagiram a crise econômica mundial de 2008. Assim, realizou-se uma pesquisa bibliográfica a partir das bases Web OfScience e Scielo, analisando trabalhos defendidos entre os anos de 2007 e 2015, indexados pelos termos: (I) A bolha imobiliária e a crise econômica mundial de 2008; (II) A crise econômica nas instituiçóes bancárias brasileiras. Os resultados apontam que os bancos brasileiros foram pouco impactados pela crise econômica mundial, pois souberam redirecionar a sua fonte de receita para produtos de baixo risco, sendo que as poucas operaçóes que oferecem maior risco sáo ofertadas para clientes que passam por criteriosa análise de crédito e apresentam garantias vinculadas às operaçóes.
\end{abstract}

Palavras-chave: Crise Econômica. Instituições Bancárias Brasileiras.

\section{THE WORLD ECONOMIC CRISIS OF 2008 AND GLARE ON BANKING INSTITUTIONS BRAZILIAN}

\begin{abstract}
This article aims to explain through the academic literature as Brazilian banks reacted to the global economic crisis of 2008. Thus, there was a literature search from Web of Science and Scielo bases, analyzing works defended between the years 2007 and 2015, indexed by the terms: (i) the property bubble and the global economic crisis of 2008; (II) The economic crisis in Brazilian banks. The results show that Brazilian banks were little affected by the global economic crisis, because they knew redirect their source of revenue for low-risk products, and the few operations that offer higher risk are offered to customers who have gone through careful analysis and presenting guarantees linked to operations.
\end{abstract}

Keywords: Economic Crisis. Brazilian Banking Institutions.

1 Graduado em Administração pelo Centro Universitário Franciscano. E-mail: henrique_fd@yahoo.com.br

2 Doutor em Administração pela Universidade de São Paulo. E-mail: mr.gmoura.ufsm@gmail.com

3 Mestranda em Administração pela Universidade Federal de Santa Maria. E-mail: marchijanaina@gmail.com 


\section{INTRODUÇÁO}

A crise financeira é um termo usado para definir uma situação de desvalorizaçáo de um ativo ou de uma instituição, pode ser gerado por estouro de bolhas financeiras, quebras ou iliquidez de grandes empresas e instituiçóes ou uma recessão financeira (BERTOLO, 2010).

Em termos gerais, a crise financeira é causada tanto por origem interna, quanto externa. A primeira ocorre devido ao fracasso das políticas nacionais, enquanto a segunda se dá a partir de uma crise internacional, que pode surgir em outro país ou regiáo, e que impacta a economia nacional por meio do comércio e de suas repercussóes financeiras (WAELTI, 2015). Nesta configuraçấo, nota-se que desde a década de 30, quando o mundo enfrentou a Grande Depressão, várias crises afetaram o cotidiano tanto da economia global, quanto das economias nacionais.

O Quadro 1 demonstra algumas crises pontuais que ocorreram entre o Crack de 29 e a Grande Recessão de 2008.

Quadro 1 - Maiores crises financeiras e do capitalismo desde 1929

\begin{tabular}{|c|c|c|c|}
\hline Crise & Ano & Descriçáao & Impactos \\
\hline $\begin{array}{c}\text { O Crack de } \\
1929\end{array}$ & $\begin{array}{r}1929 \\
-1930 \\
\end{array}$ & $\begin{array}{c}\text { Queda dos preços dos produtos agrários dos } \\
\text { Estados Unidos. }\end{array}$ & $\begin{array}{l}\text { Quedas de produçáo e de preços; } \\
\text { Queda na bolsa de valores de NY. }\end{array}$ \\
\hline $\begin{array}{l}\text { O fim do } \\
\text { padrão ouro }\end{array}$ & 1971 & $\begin{array}{l}\text { Gastos excessivos dos EUA no Exterior e a } \\
\text { Guerra do Vietnã fizeram com que as reservas } \\
\text { de ouro que o país tinha caíssem. }\end{array}$ & Desvalorização do Dólar. \\
\hline \begin{tabular}{|c|} 
Embargo \\
do petróleo \\
durante a guerra \\
Árabe-Israelense \\
\end{tabular} & 1973 & $\begin{array}{c}\text { Corte de provisão dos Estados que compóem } \\
\text { a Organização dos Países Exportadores de } \\
\text { Petróleo (Opep), provocou o aumento na } \\
\text { commodity. } \\
\end{array}$ & $\begin{array}{l}\text { Aumento da fatura energética do } \\
\text { Ocidente; } \\
\text { Crise nos países mais } \\
\text { industrializados. } \\
\end{array}$ \\
\hline $\begin{array}{l}\text { A Revolução } \\
\text { Iraniana }\end{array}$ & 1979 & $\begin{array}{l}\text { Derrocada do Xá Mohammad Reza Pahlevi e } \\
\text { a instauração da República Islâmica do Irã. }\end{array}$ & $\begin{array}{l}\text { Provoca a segunda crise do } \\
\text { petróleo, e um novo colapso } \\
\text { internacional. }\end{array}$ \\
\hline $\begin{array}{l}\text { Segunda-feira } \\
\text { Negra }\end{array}$ & 1987 & $\begin{array}{l}\text { Milhóes de investidores ao mesmo tempo } \\
\text { venderam suas açóes na Bolsa de NY devido } \\
\text { à crença da manipulaçáo de informação } \\
\text { privilegiada e à aquisiçâo de empresas com } \\
\text { dinheiro procedentes de empréstimos. }\end{array}$ & $\begin{array}{l}\text { Queda na bolsa de valores de NY; } \\
\text { Intensificaçáo da coordenação } \\
\text { monetária internacional e dos } \\
\text { principais assuntos econômicos. }\end{array}$ \\
\hline $\begin{array}{l}\text { Crise das } \\
\text { pontocom }\end{array}$ & 2000 & $\begin{array}{l}\text { Excessos da nova economia deixaram } \\
\text { uma esteira de falências, fechamentos, } \\
\text { compras e fusóes no setor da internet e das } \\
\text { telecomunicaçóes. }\end{array}$ & $\begin{array}{l}\text { Em três anos a crise apaga do mapa } \\
\text { quase cinco mil companhias; } \\
\text { Algumas das grandes corporaçóes } \\
\text { de telecomunicaçóes foram } \\
\text { protagonistas dos maiores } \\
\text { escândalos contábeis da história. }\end{array}$ \\
\hline 11 de Setembro & 2001 & $\begin{array}{c}\text { Atentados contra o World Trade Center } \\
\text { (Torres Gêmeas) em Nova York e o Pentágono } \\
\text { em Washington. }\end{array}$ & $\begin{array}{l}\text { Queda nas as bolsas de valores no } \\
\text { mundo todo. }\end{array}$ \\
\hline $\begin{array}{l}\text { A Grande } \\
\text { Recessão }\end{array}$ & 2008 & $\begin{array}{l}\text { Explosão de uma enorme bolha imobiliária, } \\
\text { que revelou que os bancos tinham estendido } \\
\text { hipotecas lixo (subprime) a pessoas sem } \\
\text { condiçôes de pagar. }\end{array}$ & $\begin{array}{l}\text { Os EUA sofreram a maior crise } \\
\text { financeira desde os anos } 1930 \text {, } \\
\text { consequência de um relaxamento } \\
\text { na avaliaçáo do risco. } \\
\text { - Contagiou o resto do mundo. }\end{array}$ \\
\hline
\end{tabular}

Fonte: Elaborado pelos autores, com base nas obras de Amaral (2009) e Streeck (2012). 
Observando as crises apontadas no Quadro 1, percebe-se que a crise de 2008 é qualitativamente diferente das demais crises precedentes. Ao contrário das crises das décadas de 1980, 1990 e 2000, que em geral limitaram-se a alguma parte do mundo, ou a alguns países, essa crise se estendeu ao mundo inteiro. A crise de 2008 impôs grandiosos prejuízos aos maiores conglomerados financeiros do planeta, de modo que alguns destes ficaram completamente descapitalizados, e essa retração, tal qual uma ressaca, impactou praticamente o globo como um todo (SINGER, 2009).

Nesta configuração, além da crise financeira que atingiu praticamente a todas as naçóes a partir de 2008 , a situação agravou-se, particularmente no Brasil, em virtude do reflexo sobre a economia brasileira, ou seja, da ampliaçáo da crise em meados do segundo semestre de 2008, somada a queda abrupta e acentuada da produção e do emprego, do corte do financiamento externo e da retraçáo do crédito interno, houve uma redução drástica de produçâoo das empresas (CARVALHO, 2009).

$\mathrm{Na}$ visão de Almeida et al. (2012), a crise mundial de 2008 foi gerada por meio de uma bolha imobiliária, em virtude do aquecido mercado de imóveis e das baixas taxas de juros que atraia a atençáo das pessoas desde 2006. Por exemplo, era possível conseguir elevados rendimentos com a venda de propriedades valorizadas. Neste momento, os bancos cederam inúmeros empréstimos hipotecários, sem uma minuciosa análise do perfil dos tomadores, o que permitia acesso ao crédito tanto para "bons" pagadores, quanto para pessoas com histórico de pagamentos desconhecidos e principalmente de "maus" pagadores. Essa operação por sua vez, acarretou uma inadimplência "inesperada", e consequentemente, o estouro da bolha.

Considerando-se relevante que resultados da crise de 2008 ainda estão presentes na crise brasileira que inicia em 2009, e que o impacto é sentido por toda a economia nacional, vide endividamento da população brasileira, redução da classe média, redução de geração de postos de trabalho, e que considerável parte da economia nacional depende tanto do governo, quanto das instituiçōes financeiras (CAMPOS; SOUZA; MATOS, 2015). Neste contexto, pretende-se neste trabalho buscar quais foram as reaçóes causadas nas instituiçóes bancárias brasileiras em funçáo da crise mundial de 2008. Conforme abordado por Bortoluzzi et al. (2015), Ribeiro e Lara (2016), o percentual de famílias brasileiras endividadas pulou de 20\% em 2005 para 62,5\% em 2014. Em 2008 a taxa de desemprego encontrava-se em 7,8\% (SILVA; NETO, 2014), e passou para 12,6\% em 2017, o que representa 13 milhóes de desempregados (IBGE, 2017).

Para operacionalizar este estudo, foi realizado um levantamento bibliográfico a partir do que a literatura tem publicado a respeito da crise econômica mundial de 2008 e as consequências para as instituiçóes bancárias brasileiras. Pelo trabalho possuir características descritivas e qualitativas (VIEIRA, 2004), a sistemática empregada para a coleta de dados foram as referências de artigos, teses e dissertaçóes, do banco de dados da Coordenação de Aperfeiçoamento de Pessoal de Nível Superior (CAPES), mais especificamente nas bases de dados Web Of Science e Scielo, utilizando como filtro os artigos, dissertaçóes e teses publicados e defendidos entre os anos de 2007 e 2015. Mapeados como balizadores da pesquisa, foram relacionados os assuntos: (I) A bolha imobiliária e a crise econômica mundial de 2008; (II) A crise econômica nas instituiçôes bancárias brasileiras. 
A fim de melhor entendimento desse trabalho optou-se por construí-lo em quatro tópicos. O primeiro aborda a problematização e o método de investigação, o segundo trata dos conceitos teóricos a respeito da crise financeira mundial e o reflexo nas instituiçóes bancárias nacionais. Os resultados do levantamento bibliográfico e suas análises ocorrem no terceiro tópico. Por fim, a conclusão, limitaçôes e sugestôes de investigaçôes futuras, estão presentes no quarto tópico. Os resultados da pesquisa foram analisados de forma qualitativa e as informações coletadas foram totalmente de fontes secundárias.

\section{CRISE FINANCEIRA MUNDIAL DE 2008 E O REFLEXO NAS INSTITUIÇÓES BANCÁRIAS NACIONAIS}

Este tópico tem como finalidade analisar teoricamente as investigaçôes a que este trabalho se propóe, desde a origem do colapso da economia mundial de 2008, até as consequências nas instituiçóes bancárias brasileiras.

\subsection{A bolha imobiliária e a crise econômica mundial de 2008}

A bolha imobiliária, como por exemplo, a ocorrida no Japão entre os anos de 1986 a 1991 (GRÁFICO 1), trata do aumento da demanda por imóveis e é ocasionada tanto pela facilidade de crédito, quanto pela necessidade das pessoas que não possuem residência. Porém não são acompanhadas pela oferta de imóveis disponíveis, provocando grande elevação dos preços. A demanda é gerada conforme a melhora das condições de vida da populaçáo, acréscimo de empregos e baixa taxa de juros dos financiamentos (ALLEN; CARLETTI, 2009).

Gráfico 1 - A bolha imobiliária no Japão, apresentando no eixo y o Preço dos ativos (multiplicado por mil Ienes) e no x Período (1985-2006)

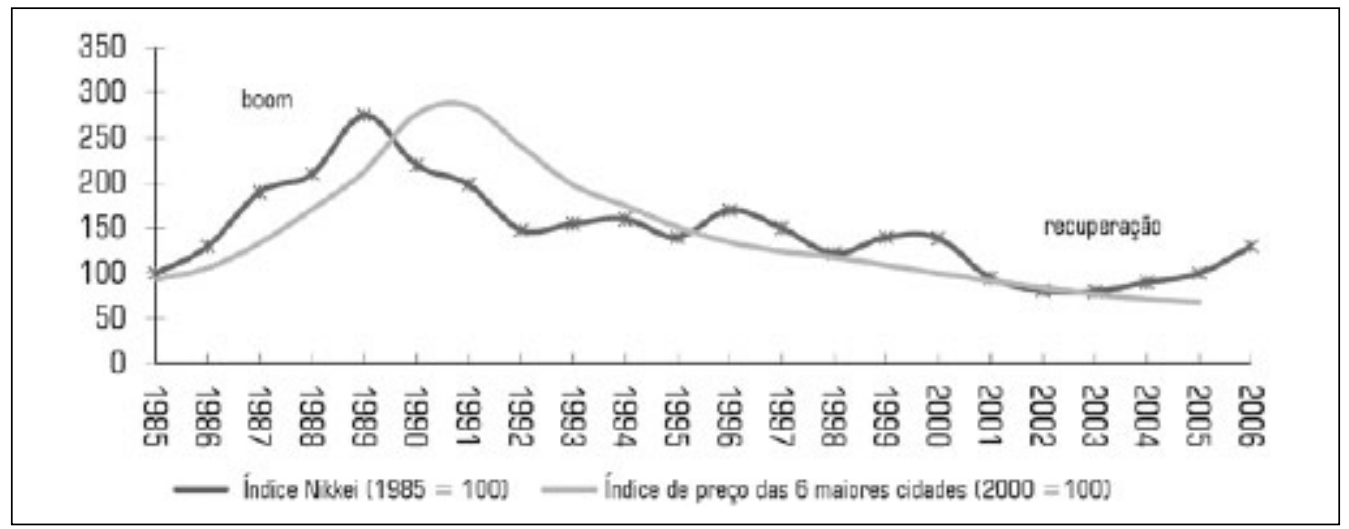

Fonte: Fraga e Strachman (2013).

A crise mundial teve origem no estouro de uma dessas bolhas imobiliárias, mais especificamente a de 2008 nos Estados Unidos, mas que já tomava forma no ano de 2007, provocada pela provisão competitiva de crédito a cada vez mais compradores de habitaçóes, cujos preços náo cessaram de subir durante cinco anos. Os novos proprietários utilizavam a 
valorização dos seus patrimônios, que serviam como garantia, para tomar mais empréstimos. $\mathrm{O}$ aumento do consumo alcançava até mesmo produtos importados, fazendo que os efeitos da bolha se propagassem pelo mundo (SINGER, 2009; DUCHIN; OZBAS; SENSOY, 2010).

Somado a crise do estouro da bolha americana no primeiro semestre de 2008, em setembro do mesmo ano, a quebra do banco americano de investimentos Lehman Brothers e o colapso da maior seguradora do mundo, resultaram em uma das maiores crises financeiras, e acabou por refletir diretamente nas demais instituiçóes financeiras dos Estados Unidos, por exemplo, Bear Stearns, Merrill Lynch, Citibank (CAMPELLO; GRAHAM; HARVEY, 2010).

A crise espalhou-se pelo mundo por meio da interdependência dos sistemas financeiros nacionais, bolhas especulativas em mercados imobiliários de outros países (Reino Unido, Espanha, Irlanda), e das seguintes quedas: demanda global, exportaçóes, atividade econômica, emprego, e dos preços das ações que forçaram governos e bancos centrais em muitas partes do mundo a seguir as políticas intervencionistas dos EUA (MOLLER; VITAL, 2013).

A redução de crédito transformou o que já era uma grande recessão, na pior recessão em 80 anos, e a recuperação permanece frágil em comparação com períodos de recuperação pós-guerra anteriores. O Produto Interno Bruto (PIB) ainda está abaixo de seu pico précrise em muitos países desenvolvidos, especialmente na Europa, onde a crise financeira evoluiu para a crise do euro (MAKKONEN et al., 2014).

\subsection{A crise econômica nas instituiçóes bancárias brasileiras}

A crise global teve contágio com a economia brasileira pela queda das exportaçóes e importações, em consequência da queda da demanda global, pela escassez de crédito, pela queda da confiança de empresários e consumidores brasileiros e pela tentativa do governo de seguir políticas protecionistas, como estimular a expansão do crédito e diminuição das taxas de juros nos bancos (CARVALHO, 2009).

Assim, a crise sistêmica global atingiu fortemente a economia brasileira tanto pela via do comércio exterior como pelos fluxos financeiros, incluindo as linhas de crédito comercial. $\mathrm{Na}$ reversão das expectativas, os bancos reagiram com excesso de prudência e retraíram fortemente o crédito, levando as empresas a rever os planos de produção e de investimento. O resultado foi a desvalorização do real, a rápida desaceleração da atividade econômica no último trimestre do ano de 2008, e a contração e "empoçamento" da liquidez (FREITAS, 2009).

A desvalorização do real frente ao dólar, iniciada em setembro de 2008, foi o fator mais relevante na hierarquia dos canais de transmissão, sobrepujando outros elementos, tais como o aumento da remessa de capitais para o exterior, a contração do crédito internacional e a forte queda dos investimentos diretos estrangeiros (CASTILHO, 2011).

Conforme analisado por Teixeira, Pinheiro e Ferreira (2013), mesmo com medidas políticas de proteção da economia adotadas pelo Governo, os impactos gerais da crise foram: a retração da atividade econômica como um todo evidenciado por meio de uma 
abrupta queda na taxa de crescimento do PIB, um déficit nas transaçóes correntes e relativa estabilidade no nível de emprego. Contudo, as políticas adotadas não foram capazes de impedir contraçóes significativas na taxa de crescimento e o resultado negativo das transaçóes correntes.

Enquanto a eficiência de lucro dentro das instituiçóes bancárias brasileiras foi afetada negativamente pela crise, a eficiência de custo foi afetada positivamente. $\mathrm{O}$ efeito positivo da crise sobre a eficiência de custo parece indicar que, durante períodos de crise, os bancos buscam maior racionalização dos componentes do custo, por se tratar de variáveis de mais fácil controle. Já os componentes da receita são os mais afetados nestes períodos, pois dependem de fatores externos aos bancos (ARANTES; ROCHA, 2012).

O governo federal, por meio do Banco do Brasil, ensejou aumentar a oferta de crédito com vistas ao estímulo ao consumo (SILVA; ALPERSTEDT, 2013). No começo, os bancos privados retraíram a oferta de crédito e elevaram as taxas de juros, porém alguns meses mais tarde, assim que o mercado verificou expansão da base de crédito, passaram também a ofertar crédito em condiçóes mais vantajosas. Mas nem mesmo essa intervenção do governo foi capaz de conter a recessão no Brasil, sendo que mais tarde as taxas de juros voltaram a aumentar e a liberação de crédito diminuiu novamente (SILVA; ALPERSTEDT, 2013).

\section{RESULTADOS E ANÁLISES}

A fim de investigar a reação das instituições bancárias brasileiras frente a crise econômica mundial de 2008, apenas sob o ponto de vista de publicaçóes, fez-se um levantamento de Abril a Junho de 2016. Para melhor entendimento dos resultados, e posterior análise, optou-se por separar os dados em dois blocos: A) A bolha imobiliária e a crise econômica mundial de 2008; B) A crise econômica nas instituições bancárias brasileiras.

\section{A) A bolha imobiliária e a crise econômica mundial de 2008}

Para estruturar as análises e resultados sobre a temática que remete especificamente à crise econômica mundial de 2008 eà bolha imobiliária, de um total 18 trabalhos encontrados, foram selecionados 12 textos de 26 autores, entre os anos de 2007 a 2015, indicando o motivo do seu início e as suas consequências. Esses 12 textos foram escolhidos, pois seus conteúdos estão totalmente de acordo com os termos pesquisadas: A bolha imobiliária e a crise econômica mundial de 2008 (QUADRO 2).

Quadro 2 - A bolha imobiliária e a crise econômica mundial de 2008

\begin{tabular}{|c|c|c|c|c|c|c|}
\hline Ano & Autor & Título & Palavras-chave & Instituiçáo & Periódico & $\begin{array}{c}\text { QUALIS } \\
\text { CAPES } \\
\text { 2012-13- } \\
\text { 14 Adm., } \\
\text { C.Cont. } \\
\text { Turismo }\end{array}$ \\
\hline 2008 & $\begin{array}{c}\text { Monteiro, } \\
\text { J. V. }\end{array}$ & $\begin{array}{c}\text { Um padrão de política } \\
\text { pública na crise } \\
\text { econômica mundial. }\end{array}$ & $\begin{array}{c}\text { Crise econômica, } \\
\text { Políticas públicas, } \\
\text { Política e a economia. }\end{array}$ & $\begin{array}{c}\text { Escola Brasileira } \\
\text { de Administraçáo } \\
\text { Pública e de } \\
\text { Empresas - } \\
\text { Ebape-FGV }\end{array}$ & $\begin{array}{c}\text { RAP - Revista de } \\
\text { Administraçáo } \\
\text { Pública. }\end{array}$ & ISSN 0034-7612 \\
\hline
\end{tabular}




\begin{tabular}{|c|c|c|c|c|c|c|}
\hline Ano & Autor & Título & Palavras-chave & Instituiçáoo & Periódico & $\begin{array}{l}\text { QUALIS } \\
\text { CAPES } \\
\text { 2012-13- } \\
14 \text { Adm., } \\
\text { C.Cont. } \\
\text { Turismo }\end{array}$ \\
\hline 2009 & Singer,P. & $\begin{array}{l}\text { A América Latina na } \\
\text { crise mundial. }\end{array}$ & $\begin{array}{c}\text { Crise financeira } \\
\text { internacional, } \\
\text { Globalização } \\
\text { financeira, Estatização } \\
\text { de bancos falidos, } \\
\text { Bancos públicos, } \\
\text { Estatização da } \\
\text { atividade financeira. } \\
\end{array}$ & $\begin{array}{l}\text { Universidade de } \\
\text { São Paulo } \\
\text { USP }\end{array}$ & $\begin{array}{c}\text { REA - Revista } \\
\text { Estudos Avançados } \\
\text { ISSN 1806-9592 }\end{array}$ & B2 \\
\hline 2009 & $\begin{array}{c}\text { McKibbin, } \\
\text { W.; Stoeckel, } \\
\text { A. }\end{array}$ & $\begin{array}{c}\text { The Global Financial } \\
\text { Crisis: } \\
\text { Causes and } \\
\text { Consequences }\end{array}$ & $\begin{array}{c}\text { Global Financial } \\
\text { Crisis, International } \\
\text { Trade, DSGE models. }\end{array}$ & $\begin{array}{l}\text { Australian } \\
\text { National } \\
\text { University }\end{array}$ & $\begin{array}{c}\text { International } \\
\text { Economy Program } \\
\text { ISSN 0925-5273 }\end{array}$ & A1 \\
\hline 2009 & $\begin{array}{l}\text { Allen, F.; } \\
\text { Carletti, E. }\end{array}$ & $\begin{array}{l}\text { The Global Financial } \\
\text { Crisis: Causes and } \\
\text { Consequences. }\end{array}$ & $\begin{array}{c}\text { Financial crisis, Real } \\
\text { estate bubble, Causes } \\
\text { and consequences of } \\
\text { the crisis. }\end{array}$ & $\begin{array}{c}\text { University of } \\
\text { Pennsylvania } \\
\text { e European } \\
\text { University } \\
\text { Institute } \\
\end{array}$ & $\begin{array}{c}\text { Journal of } \\
\text { Monetary } \\
\text { Economics } \\
\text { ISSN 0304-3932 }\end{array}$ & A1 \\
\hline 2010 & $\begin{array}{l}\text { Campello, } \\
\text { M.; Graham, } \\
\text { J.R.; Harvey, } \\
\text { C.R. }\end{array}$ & $\begin{array}{l}\text { The real effects of } \\
\text { financial constraints: } \\
\text { Evidence from a } \\
\text { financial crisis. }\end{array}$ & $\begin{array}{c}\text { Financial crisis, } \\
\text { Financing constraints, } \\
\text { Investment } \\
\text { spending, Liquidity } \\
\text { management. } \\
\end{array}$ & $\begin{array}{l}\text { University of } \\
\text { Illinois e Duke } \\
\text { University }\end{array}$ & $\begin{array}{l}\text { Journal of Financial } \\
\text { Economics } \\
\text { ISSN 0304-405X }\end{array}$ & A1 \\
\hline 2010 & $\begin{array}{l}\text { Duchin, R.; } \\
\text { Ozbas, O.; } \\
\text { Sensoy, B. }\end{array}$ & $\begin{array}{c}\text { Costly external finance, } \\
\text { corporate investment, } \\
\text { and the subprime } \\
\text { mortgage credit crisis. }\end{array}$ & $\begin{array}{c}\text { Corporate investment, } \\
\text { Cash Corporate } \\
\text { liquidity, Financing } \\
\text { constraints, Financial } \\
\text { crisis. }\end{array}$ & $\begin{array}{c}\text { University } \\
\text { of Michigan, } \\
\text { University of } \\
\text { Southern e Ohio } \\
\text { State University }\end{array}$ & $\begin{array}{l}\text { Journal of Financial } \\
\text { Economics } \\
\text { ISSN 0304-405X }\end{array}$ & A1 \\
\hline 2010 & Pereira, L.C. & $\begin{array}{c}\text { A crise financeira global } \\
\text { e depois: um novo } \\
\text { capitalismo? }\end{array}$ & $\begin{array}{c}\text { Crise financeira, } \\
\text { Desregulação, } \\
\text { Neoliberalismo, } \\
\text { Coalizão política. } \\
\end{array}$ & $\begin{array}{c}\text { Fundação Getúlio } \\
\text { Vargas - FGV }\end{array}$ & $\begin{array}{l}\text { CEBRAP - Revista } \\
\text { Novos Estudos } \\
\text { ISSN } \underline{0101-3300}\end{array}$ & A2 \\
\hline 2012 & $\begin{array}{l}\text { Almeida, } \\
\text { M. S.; } \\
\text { Bertucci, L. } \\
\text { A. Francisco, } \\
\text { J. R.; Amaral, } \\
\text { H. F. }\end{array}$ & $\begin{array}{c}\text { Influência da crise } \\
\text { financeira mundial } \\
\text { na estrutura } \\
\text { econômica das } \\
\text { instituiçóes financeiras } \\
\text { bancárias brasileiras } \\
\text { e seus reflexos no } \\
\text { índice de Basiléia: } \\
\text { Uma abordagem } \\
\text { comparativa. }\end{array}$ & $\begin{array}{c}\text { Instituiçóes } \\
\text { financeiras, Índice } \\
\text { de Basiléia, Crise } \\
\text { financeira. }\end{array}$ & $\begin{array}{l}\text { Universidade de } \\
\text { Sáo Paulo } \\
\text { USP }\end{array}$ & $\begin{array}{c}\text { RCO - Revista de } \\
\text { Contabilidade e } \\
\text { Organizaçóes ISSN } \\
1982-6486\end{array}$ & B1 \\
\hline 2013 & $\begin{array}{l}\text { Moller, H.D.; } \\
\text { Vital, T. }\end{array}$ & $\begin{array}{l}\text { Os impactos da crise } \\
\text { financeira global } \\
2008 / 09 \text { e da crise } \\
\text { na área de euro desde } \\
2010 \text { sobre a balança } \\
\text { comercial brasileira. }\end{array}$ & $\begin{array}{c}\text { Crise financeira global, } \\
\text { Crise na área do euro, } \\
\text { Balança comercial } \\
\text { brasileira. }\end{array}$ & $\begin{array}{l}\text { Universidade } \\
\text { de São Paulo } \\
\text { USP, Campus de } \\
\text { Ribeirão Preto }\end{array}$ & $\begin{array}{l}\text { RACEF - Revista } \\
\text { de Administraçăo, } \\
\text { Contabilidade } \\
\text { e Economia da } \\
\text { FUNDACE } \\
\text { ISSN 2178-7638 } \\
\end{array}$ & \\
\hline 2013 & Ferraz, F. C. & $\begin{array}{l}\text { Crise financeira global: } \\
\text { impactos na economia } \\
\text { brasileira, política } \\
\text { econômica e resultados. }\end{array}$ & $\begin{array}{c}\text { Crise do subprime, } \\
\text { Economia brasileira, } \\
\text { Crise econômica } \\
\text { mundial, Política fiscal } \\
\text { e creditícia, Política } \\
\text { anticíclica. } \\
\end{array}$ & $\begin{array}{c}\text { Universidade } \\
\text { Federal do Rio de } \\
\text { Janeiro - UFRJ }\end{array}$ & $\begin{array}{l}\text { Dissertação de } \\
\text { mestrado }\end{array}$ & \\
\hline
\end{tabular}




\begin{tabular}{|c|c|c|c|c|c|c|}
\hline Ano & Autor & Título & Palavras-chave & Instituiçáoo & Periódico & $\begin{array}{l}\text { QUALIS } \\
\text { CAPES } \\
2012-13- \\
14 \text { Adm., } \\
\text { C.Cont. } \\
\text { Turismo }\end{array}$ \\
\hline 2013 & $\begin{array}{l}\text { Bezerra, M. } \\
\text { M.; Correa, } \\
\text { A. L.; } \\
\text { Mendonça, } \\
\text { A. R.; } \\
\text { Clementino, } \\
\text { M. L. } \\
\end{array}$ & $\begin{array}{c}\text { Formação, sustentação } \\
\text { ou implosão de uma } \\
\text { bolha imobiliária? A } \\
\text { dinâmica de preços de } \\
\text { imóveis de Natal de } \\
2005-2010 .\end{array}$ & $\begin{array}{l}\text { Bolha imobiliária, } \\
\text { Capital estrangeiro, } \\
\text { Crédito imobiliário. }\end{array}$ & $\begin{array}{l}\text { Universidade } \\
\text { Estadual de } \\
\text { Campinas - } \\
\text { UNICAMP }\end{array}$ & $\begin{array}{l}\text { RES - Revista } \\
\text { Economia e } \\
\text { Sociedade } \\
\text { ISSN 1982-3533 }\end{array}$ & B1 \\
\hline 2014 & $\begin{array}{c}\text { Makkonen, } \\
\text { H.; Pohjola, } \\
\text { M.; } \\
\text { Olkkonen, } \\
\text { R.; Koponen, } \\
\text { A. } \\
\end{array}$ & $\begin{array}{l}\text { Dynamic capabilities } \\
\text { and firm performance } \\
\text { in a financial crisis. }\end{array}$ & $\begin{array}{l}\text { Dynamic capabilities, } \\
\text { Innovation, Business } \\
\text { environment, } \\
\text { Financial crisis, } \\
\text { Firm performance. }\end{array}$ & $\begin{array}{c}\text { University of } \\
\text { Turku e Ultrecht } \\
\text { University School } \\
\text { of Economics }\end{array}$ & $\begin{array}{l}\text { Journal of Business } \\
\text { Research } \\
\text { ISSN 0148-2963 }\end{array}$ & A1 \\
\hline
\end{tabular}

Fonte: Elaborado pelos autores.

\section{B) A crise econômica nas instituiçóes bancárias brasileiras}

Para analisar a temática que leva especificamente à crise econômica nas instituiçóes bancárias brasileiras, de um total de 21 obras, foram destacados 15 textos de 28 autores entre os anos de 2007 a 2015, que mais se adéquam com os termos pesquisados: A crise econômica nas instituições bancárias brasileiras (QUADRO 3).

Quadro 3 - A crise econômica brasileira

\begin{tabular}{|c|c|c|c|c|c|c|}
\hline Ano & Autor & Título & Palavras-chave & Instituiçãoo & Periódico & $\begin{array}{l}\text { QUALIS } \\
\text { CAPES } \\
\text { 2012-13- } \\
14 \text { Adm., } \\
\text { C.Cont. } \\
\text { Turismo }\end{array}$ \\
\hline 2009 & $\begin{array}{l}\text { Freitas, M. } \\
\text { C. P. }\end{array}$ & $\begin{array}{c}\text { Os efeitos da crise } \\
\text { global } \\
\text { no Brasil: aversão ao } \\
\text { risco } \\
\text { e preferência pela } \\
\text { liquidez } \\
\text { no mercado de crédito. }\end{array}$ & $\begin{array}{l}\text { Crise sistêmica, Pre- } \\
\text { ferência pela liquidez, } \\
\text { Bancos, Contração do } \\
\text { crédito, Brasil. }\end{array}$ & $\begin{array}{c}\text { Universidade } \\
\text { Estadual de } \\
\text { Campinas - UNI- } \\
\text { CAMP }\end{array}$ & $\begin{array}{c}\text { REA - Revista Estu- } \\
\text { dos Avançados } \\
\text { ISSN 1806-9592 }\end{array}$ & B2 \\
\hline 2009 & $\begin{array}{l}\text { Monteiro, } \\
\text { J. V. }\end{array}$ & $\begin{array}{c}\text { Governança da crise } \\
\text { econômica }\end{array}$ & $\begin{array}{l}\text { Liçóes da crise de } \\
\text { 2008, Crise e estado } \\
\text { administrativo. }\end{array}$ & $\begin{array}{c}\text { Escola Brasileira } \\
\text { de Administra- } \\
\text { ção Pública e de } \\
\text { Empresas - Ebape- } \\
\text {-FGV }\end{array}$ & $\begin{array}{l}\text { RAP - Revista de } \\
\text { Administraçá́o } \\
\text { Pública. } \\
\text { ISSN 0034-7612 }\end{array}$ & $\mathrm{A} 2$ \\
\hline 2009 & $\begin{array}{l}\text { Monteiro, } \\
\text { J. V. }\end{array}$ & $\begin{array}{l}\text { Percepções analíticas } \\
\text { da crise econômica e } \\
\text { racionalidade política }\end{array}$ & $\begin{array}{l}\text { Dinâmica da crise, } \\
\text { Racionalidade das } \\
\text { regras eleitorais. }\end{array}$ & $\begin{array}{c}\text { Escola Brasileira } \\
\text { de Administra- } \\
\text { ção Pública e de } \\
\text { Empresas - Ebape- } \\
\text {-FGV }\end{array}$ & $\begin{array}{l}\text { RAP - Revista de } \\
\text { Administraçáo } \\
\text { Pública. } \\
\text { ISSN 0034-7612 }\end{array}$ & $\mathrm{A} 2$ \\
\hline 2009 & $\begin{array}{l}\text { Carvalho, } \\
\text { C. E. }\end{array}$ & $\begin{array}{l}\text { A crise internacional } \\
\text { desafia o modelo bra- } \\
\text { sileiro de abertura e } \\
\text { liberalização }\end{array}$ & $\begin{array}{c}\text { Crise internacional, } \\
\text { Economia brasileira, } \\
\text { Modelo brasileiro de } \\
\text { abertura e liberali- } \\
\text { zaçáo. }\end{array}$ & $\begin{array}{l}\text { Universidade de } \\
\text { São Paulo } \\
\text { USP }\end{array}$ & $\begin{array}{c}\text { REA - Revista Estu- } \\
\text { dos Avançados } \\
\text { ISSN 1806-9592 }\end{array}$ & B2 \\
\hline
\end{tabular}




\begin{tabular}{|c|c|c|c|c|c|c|}
\hline Ano & Autor & Título & Palavras-chave & Instituiçáo & Periódico & $\begin{array}{l}\text { QUALIS } \\
\text { CAPES } \\
\text { 2012-13- } \\
14 \text { Adm., } \\
\text { C.Cont. } \\
\text { Turismo } \\
\end{array}$ \\
\hline 2011 & Castilho, M. & $\begin{array}{c}\text { Impactos da Crise } \\
\text { Econômica Internacio- } \\
\text { nal Sobre O Comércio } \\
\text { Exterior Brasileiro. }\end{array}$ & $\begin{array}{c}\text { Crise, Recessão Eco- } \\
\text { nômica, Mercado } \\
\text { Financeiro, Comércio } \\
\text { Exterior, Países em } \\
\text { Desenvolvimento, } \\
\text { Brasil. } \\
\end{array}$ & $\begin{array}{l}\text { IPEA - Instituto } \\
\text { de Pesquisa Eco- } \\
\text { nômica Aplicada }\end{array}$ & Livro & \\
\hline 2012 & $\begin{array}{l}\text { Arantes, T. } \\
\text { M. e Rocha, } \\
\text { B. P. }\end{array}$ & $\begin{array}{l}\text { Eficiência dos bancos } \\
\text { brasileiros e os impac- } \\
\text { tos da crise financeira } \\
\text { global de } 2008 .\end{array}$ & $\begin{array}{l}\text { Crise financeira glo- } \\
\text { bal, Eficiência, Setor } \\
\text { bancário brasileiro. }\end{array}$ & $\begin{array}{l}\text { Universidade de } \\
\text { Brasília - UnB }\end{array}$ & $\begin{array}{c}\text { ANPEC - Revista } \\
\text { da Associação Nac. } \\
\text { dos Centros de Pós- } \\
\text {-Grad. em Econ. } \\
\text { ISSN:1517-7580 } \\
\end{array}$ & B1 \\
\hline 2012 & $\begin{array}{c}\text { Gonçalves, R. } \\
\text { S.; Tavares, A. } \\
\text { L.; Ximenes, } \\
\text { P. e Silva, R. } \\
\text { M. }\end{array}$ & $\begin{array}{c}\text { Comportamento dos } \\
\text { Dez Maiores Bancos } \\
\text { Bras. Durante a Crise } \\
\text { Subprime: uma Análise } \\
\text { por Meio de Indicado- } \\
\text { res Contábeis }\end{array}$ & $\begin{array}{l}\text { Análise de Balanço, } \\
\text { Instituiçóes Financei- } \\
\text { ras, Crise do subpri- } \\
\text { me. }\end{array}$ & $\begin{array}{l}\text { Universidade de } \\
\text { Brasília - UnB }\end{array}$ & $\begin{array}{c}\text { REPEC - Revista } \\
\text { de Educ. e Pesq em } \\
\text { Contabilidade } \\
\text { ISSN: } 1981-8610\end{array}$ & B3 \\
\hline 2013 & Pereira, J. M. & $\begin{array}{c}\text { A economia brasileira } \\
\text { diante da crise mun- } \\
\text { dial: fragilidades e } \\
\text { perspectivas de cresci- } \\
\text { mento. }\end{array}$ & $\begin{array}{c}\text { Mudança no Cenário } \\
\text { Mundial, Política Eco- } \\
\text { nômica, Perspectivas } \\
\text { de Crescimento. }\end{array}$ & $\begin{array}{l}\text { Universidade de } \\
\text { Brasília - UnB }\end{array}$ & $\begin{array}{c}\text { RECFin - Revista } \\
\text { Evidenciação Con- } \\
\text { tábil e Financeira } \\
\text { ISSN: } 2318-1001\end{array}$ & B4 \\
\hline 2013 & $\begin{array}{l}\text { Silva, A. D.; } \\
\text { e Alperstedt, } \\
\text { G. D. }\end{array}$ & $\begin{array}{c}\text { Mudança organizacio- } \\
\text { nal estratégica em um } \\
\text { banco público: uma } \\
\text { análise a partir da perda } \\
\text { da conta movimento. }\end{array}$ & $\begin{array}{l}\text { Banco do Brasil; } \\
\text { mudança; estratégia; } \\
\text { contexto. }\end{array}$ & $\begin{array}{c}\text { Escola Brasileira } \\
\text { de Administra- } \\
\text { ção Pública e de } \\
\text { Empresas - Ebape- } \\
\text {-FGV } \\
\end{array}$ & $\begin{array}{l}\text { RAP - Revista de } \\
\text { Administraçáo } \\
\text { Pública. ISSN } \\
0034-7612\end{array}$ & $\mathrm{~A} 2$ \\
\hline 2013 & $\begin{array}{c}\text { Teixeira, J. R.; } \\
\text { Pinheiro, D. } \\
\text { S.; Ferreira, } \\
\text { P. F. } \\
\end{array}$ & $\begin{array}{c}\text { Política econômica } \\
\text { brasileira } \\
\text { frente à crise mundial } \\
\text { recente: } \\
\text { uma análise baseada nas } \\
\text { contribuiçóes de Kaldor }\end{array}$ & \begin{tabular}{|c|} 
Quadrado mágico; \\
controvérsia Kaldo- \\
riana; gestão governa- \\
mental; crise econômi- \\
ca brasileira. \\
\end{tabular} & $\begin{array}{l}\text { Universidade de } \\
\text { Brasília - UnB }\end{array}$ & $\begin{array}{l}\text { RSP - Revista do } \\
\text { Serviço Público } \\
\text { ISSN: 0034-9240 }\end{array}$ & B1 \\
\hline 2013 & Ferraz, F. C. & $\begin{array}{c}\text { Crise financeira global: } \\
\text { impactos na economia } \\
\text { brasileira, política eco- } \\
\text { nômica e resultados. }\end{array}$ & \begin{tabular}{|c|} 
Crise do Subprime, \\
Economia Brasileira, \\
Política Monetária, \\
Política Fiscal e Cre- \\
ditícia, Atuação do \\
Banco Central e Políti- \\
ca Anticíclica. \\
\end{tabular} & $\begin{array}{c}\text { Universidade } \\
\text { Federal do Rio de } \\
\text { Janeiro - UFRJ }\end{array}$ & $\begin{array}{l}\text { Dissertação de } \\
\text { mestrado }\end{array}$ & \\
\hline 2013 & $\begin{array}{l}\text { Silva, A. F.; } \\
\text { Weffort, E. F.; } \\
\text { Flores, E.S; } \\
\text { Silva, G.P. }\end{array}$ & $\begin{array}{c}\text { Earnings management } \\
\text { and economic crises } \\
\text { in the brazilian capital } \\
\text { market }\end{array}$ & $\begin{array}{c}\text { Earnings management, } \\
\text { macroeconomic fac- } \\
\text { tors, economic crises, } \\
\text { emerging capital } \\
\text { markets, Brazil. } \\
\end{array}$ & $\begin{array}{l}\text { Fundação Getú- } \\
\text { lio Vargas - São } \\
\text { Paulo - FGV }\end{array}$ & $\begin{array}{c}\text { RAE - Revista de } \\
\text { Administração de } \\
\text { Empresas. ISSN } \\
0034-7590\end{array}$ & A2 \\
\hline 2014 & $\begin{array}{c}\text { Ribeiro, F. V., } \\
\text { e Schiozer, } \\
\text { R. F. }\end{array}$ & $\begin{array}{c}\text { Cessão de crédito e } \\
\text { restriçáo de capital: } \\
\text { um estudo com bancos } \\
\text { brasileiros }\end{array}$ & $\begin{array}{c}\text { Cessão, coobrigação, } \\
\text { crédito, restriçâao de } \\
\text { capital, liquidez ban- } \\
\text { cária. }\end{array}$ & $\begin{array}{c}\text { Fundação Getúlio } \\
\text { Vargas - FGV }\end{array}$ & $\begin{array}{c}\text { RAE - Revista de } \\
\text { Administração de } \\
\text { Empresas ISSN: } \\
1676-5648\end{array}$ & A2 \\
\hline 2015 & $\begin{array}{l}\text { Campos, K.; } \\
\text { Souza, M. } \\
\text { M. e Matos, } \\
\text { L. S. }\end{array}$ & $\begin{array}{c}\text { Impacto da Crise } \\
\text { Econômica do Crédito } \\
\text { nos Indicadores de De- } \\
\text { sempenho dos Maiores } \\
\text { Bancos Brasileiros: } \\
\text { Uma Análise entre os } \\
\text { Anos de } 2005 \text { a } 2012 .\end{array}$ & $\begin{array}{l}\text { Bancos, Crise econô- } \\
\text { mica, Impacto nos } \\
\text { indicadores. }\end{array}$ & $\begin{array}{l}\text { Universidade Fe- } \\
\text { deral de Campina } \\
\text { Grande-UFCG }\end{array}$ & $\begin{array}{l}\text { REUNIR - Revista } \\
\text { de Administração, } \\
\text { Contabilidade e } \\
\text { Sustentabilidade } \\
\text { ISSN: } 2237-3667\end{array}$ & B3 \\
\hline
\end{tabular}

Fonte: Elaborado pelos autores. 
A análise das referências dos Quadros 2 e 3 dá-se por duas formas - uma em que se verificam os dados técnicos, ano de publicação, autor, palavras-chave, instituição de origem, e qualis. Esse último será mencionado para nortear os pesquisadores quanto a relevância das obras selecionadas. Neste sentido, resumidamente tem-se um total de 27 trabalhos analisados, de 54 diferentes autores, publicados entre os anos de 2007 e 2015. Do total, cinco destes trabalhos possuem qualis capes A1, seis A2, quatro B1, três B2, dois B3, um B4 e quatro não possuem qualis capes, por serem dissertações, livros ou por não possuírem classificação nos últimos quatro anos.

A segunda forma, proposta de investigação deste artigo, trata dos conteúdos desenvolvidos nessas referências apontadas nos Quadros 2 e 3.

Com base nos dados do Quadro 2, têm-se as seguintes percepçóes conforme a temática bolha imobiliária e a crise econômica mundial de 2008:

- Todos os autores citados no Quadro 2 convergem no sentido de que a crise financeira econômica mundial de 2008 iniciou devido ao estouro de uma bolha imobiliária nos Estados Unidos, provocada pela provisão competitiva de crédito a cada vez mais compradores de habitaçóes, gerando uma demanda em contínuo aumento por imóveis.

- A bolha imobiliária que estourou nos EUA em 2008 teve características semelhantes com a que ocorreu no Japão na década de 1990, conforme mencionou Allen e Carletti (2009), resultado da alta demanda por imóveis, perante a baixa oferta, fazendo com que os imóveis disponíveis no mercado tivessem seus valores alavancados desproporcionalmente comparados a inflação. Tal situação é característica de economia de mercado livre, em que não há nenhuma instância que concilie os interesses de vendedores e compradores, assim como foi abordado por Singer (2009) e Bezerra et al. (2013). Soma-se a este fato, a concessão incomensurável de empréstimos a credores sem condições de honrar com o pagamento, e também a inovaçóes financeiras para securitizar os títulos destes empréstimos, dando-lhes a classificação de títulos "excelentes", como foi observado por Almeida et al. (2012).

- O colapso financeiro foi exposto ao restante do mundo com a notícia da quebra de um dos maiores bancos americanos, o Lehman Brothers, desencadeando a mais grave crise desde a grande depressão da década de 1930, como foi observado por Ferraz (2013), Moller e Vital (2013). Sob o ponto de vista político, o governo dos EUA empregou medidas de interesse geral, assim como referiu Monteiro (2008), utilizando políticas fiscais e monetárias prolongadas para salvar o país, e ajudar que o restante da economia global não entrasse em uma nova depressão.

- Mckibbin e Stoeckel (2009) possuem um entendimento de que o mundo poderia ter escapado da recessão se não houvesse em outros países o contágio de reavaliação de riscos. A desaceleração dos EUA teria sido compensada por redistribuição global do capital. A China, por exemplo, poderia ter ressurgido com força e conduzido o mundo para longe do colapso. 
- Pereira (2010) explora um conceito de que a crise financeira global de 2008 foi consequência do processo de financeirização, a criação de riqueza financeira fictícia iniciada na década de 1980, e da hegemonia de uma ideologia reacionária, o neoliberalismo, baseada em mercados autorregulados e eficientes.

- A bolha imobiliária deixou reflexos não só em empresas do ramo financeiro, e no ponto de vista de Duchin, Ozbas e Sensoy (2010) e Campello, Graham e Harvey (2010), as empresas americanas tiveram grandes perdas, e as que mais sofreram com o colapso econômico foram as que possuíam poucas reservas, tinham muitas dívidas a curto prazo e dependiam diretamente de financiamento externo. Já para Makkonen et al. (2014), a crise financeira mundial teve grande valia no ramo empresarial, pois as empresas visualizaram novas oportunidades e ativaram o seu potencial de renovação.

Posicionamento dos autores citados no Quadro 3, conforme a crise econômica nos bancos brasileiros:

- Contrastando com o intenso engajamento dos legisladores norte-americanos para conter a crise, ao chegar ao Brasil, ela depara-se com um Congresso Nacional letárgico e pouco predisposto a conter o seu avanço, como foi observado por Monteiro (2009). No ponto de vista de Carvalho (2009), o Brasil teve boa resistência a crise nos primeiros meses de 2009, pois mesmo com a intensa queda de produção e investimentos, não houve crise cambial, fiscal, devido a adoção de medidas anticíclicas, com corte de impostos e redução dos juros.

- Com o aumento das incertezas no último trimestre de 2008, diante do cenário de oscilação econômica, Freitas (2009), observou que os bancos, além de elevar as exigências de garantias para oferecer ou renovar as linhas de crédito, aumentaram as taxas de juros das operaçóes ativas.

- No ponto de vista de eficiência de custo e lucro das instituiçóes financeiras brasileiras durante o colapso de 2008, Arantes e Rocha (2012) verificaram que a escassez de dinheiro no mercado interbancário parece ter incentivado os bancos a utilizarem os recursos disponíveis de forma mais eficiente, o que aumentou a eficiência de custo. Por outro lado, a queda na atividade econômica e a maior preferência dos bancos por liquidez reduziram a capacidade de geração de receitas sobre operaçóes de crédito (principal fonte de receita), porém aumentou significativamente o lucro com o reajuste das tarifas sobre os produtos e serviços.

- Já no ano de 2009, Gonçalves et al. (2012) concluíram que apesar de um cenário controverso à expansão do crédito devido à instabilidade gerada no mercado, houve um crescimento nas operaçóes de crédito no Brasil, impulsionado, em um primeiro momento, pelos bancos públicos e depois acompanhado pelos privados, ou seja, a maioria dos bancos apresentou uma tendência anticíclica de fomentar as atividades produtivas em tempos de depressão da economia. Essa situação vem de encontro com o que foi abordado por Silva e Alperstedt (2013), em que governo federal adotou a estratégia de redução dos juros bancários para estimular o acesso ao crédito, o que no período contribuíram para que os impactos da crise 
do subprime fossem processados com menores danos para economia, confirmada em uma situação atual que apresenta sintomas de retomada do crescimento.

- Em 2012, a balança comercial brasileira teve seu pior resultado em 10 anos, sendo que a diferença entre as exportaçóes e importaçóes só não foi mais profunda porque as importaçóes foram reduzidas, conforme foi abordado por Teixeira, Pinheiro e Ferreira (2013), e Pereira (2013), sendo que os problemas a serem enfrentados pelo Brasil, não se resumem apenas ao baixo crescimento da economia, pois o país possui fragilidades do ponto de vista socioeconômico e político, em especial, a baixa qualidade dos serviços públicos, a corrupção e a falta de ética na política. Silva et al. (2013), assim como Ferraz (2013), analisaram que embora o governo juntamente com os bancos tenham implementado algumas medidas para amortecer os impactos da crise, como políticas anticíclicas, e também vinha mantendo inúmeros estímulos, essa hiperatividade tem aspectos conflitantes, pois são essencialmente pontuais, uma vez que não focam os conhecidos obstáculos estruturais ao crescimento sustentável, especialmente no que tange ao investimento produtivo.

- Mesmo de maneira leve ou moderada, Ribeiro e Schiozer (2014) e Campos, Souza e Matos (2015), analisaram que a crise gerou reflexos nos indicadores dos maiores bancos brasileiros, sendo que alguns tiveram impactos leves e outros moderados, mas de maneira geral, a crise não impactou de maneira grave e generalizada, conforme foi possível verificar nos resultados demonstrados.

Conforme se observou por meio das literaturas publicadas e estudadas (QUADROS 2 e 3), a crise econômica mundial de 2008 gerou reflexo nas instituições bancárias brasileiras devido ao colapso que começou a se desencadear entre os anos de 2007 e 2008 nos Estados Unidos, quando ocorreu o estouro de uma bolha imobiliária provocada pela valorização dos imóveis, ao qual eram usados pelos proprietários como garantias em operaçóes para a tomada de crédito, sendo que mais tarde não conseguiram pagar. $\mathrm{O}$ estouro dessa bolha imobiliária resultou na quebra de um dos maiores bancos americanos, o Lehman Brothers, e o colapso da maior seguradora do mundo. Em virtude do grande peso que os Estados Unidos apresenta perante a economia mundial, e pela magnitude que a globalização financeira atingira, a crise afetou o restante do mundo, não deixando de fora o Brasil.

No Brasil, a crise começou pela queda das exportaçóes em consequência da diminuiçáo da demanda global, e pela escassez de crédito. Para tentar amenizar ou até mesmo travar essa crise no país, o governo lançou políticas protecionistas, como estimular a expansão do crédito para consumo e investimentos, diminuição das taxas de juros nos bancos e aumento dos gastos financiados pelo BNDES. Porém esse cenário náo se sustentou, pois mesmo com as políticas adotadas, o governo não conseguiu conter as retrações do mercado e do PIB.

Com todos esses acontecimentos, ocorreu o desaquecimento da economia brasileira, gerando um efeito cascata, onde os bancos, que já vislumbravam uma diminuição em sua receita, tiveram que adotar algumas mudanças, e viram como alternativa aumentar seus lucros, e a redução dos custos, que dentre outras consequências, gerou demissões. Além disso, e com a finalidade de proteger o seu patrimônio e evitar o aumento da inadimplência, que 
já começara a tomar uma maior proporção, as instituiçóes bancárias brasileiras aumentaram as taxas de juros e o rigor nas análises do risco de crédito.

\section{CONSIDERAÇÓES FINAIS}

O presente artigo teve como objetivo analisar as consequências da crise economia mundial de 2008 para as instituiçóes bancárias brasileiras. Este estudo procurou colaborar no sentido de sistematizar informações e explicar através da literatura como as instituiçóes bancárias brasileiras reagiram frente a crise econômica mundial de 2008, uma vez que se entende a importância de compreender os efeitos dessa conjuntura a nível global.

No começo do ano de 2009, as instituiçôes bancárias brasileiras, apesar de um cenário contrário a expansão de crédito, foram estimuladas pelo governo federal a aumentar a liberação de linhas de crédito, a fim de aquecer o mercado e provar que a crise dos EUA não traria consequências para o Brasil. No primeiro momento, essa ação foi feita somente pelos bancos públicos, porém logo em seguida foram acompanhados pelos privados. Com o estímulo ao consumo e facilidade de acesso ao crédito, as empresas e pessoas físicas alavancaram consideravelmente o seu endividamento, e muitas vezes não tiveram condiçóes de honrar com seus compromissos, resultando no aumento da inadimplência bancária, o que afetou a todos os ramos empresariais.

Visualizando essa nova situação do mercado, os bancos voltaram a aumentar as taxas de juros, e passaram a adotar uma postura mais criteriosa de análise de crédito e vinculação de garantia às operaçóes, consequentemente diminuindo a circulação de dinheiro no país e amenizando a inadimplência.

Com esse novo cenário na economia brasileira, os bancos tiveram redução em suas receitas provenientes de operaçóes de crédito. Além disso, passaram a reduzir seu custo operacional, demitindo funcionários. Pode-se perceber que as instituições bancárias brasileiras foram pouco impactadas com a crise econômica mundial, pois souberam redirecionar a sua fonte de receita para operaçóes que apresentam baixo risco, sendo que as poucas operaçóes que oferecem maior risco são ofertadas em sua maioria para clientes que passaram por criteriosa análise de risco e que possam vincular garantias as operaçóes.

Como limitação, ressalta-se que foi uma análise da literatura já publicada referente ao assunto, e que uma pesquisa de campo realizada diretamente com as instituiçóes bancárias poderia agregar maior valor ao trabalho, por meio de coleta de dados primários, aplicação de questionários e entrevistas.

\section{REFERÊNCIAS}

ALLEN, F, CARLETTI, E. The Global Financial Crisis: Causes and Consequences. Journal of Monetary Economics, 2009.

ALMEIDA, M. S., BERTUCCI, L. A., FRANCISCO, J. R., AMARAL, H. F. Influência da crise financeira mundial na estrutura econômica das instituições financeiras bancárias 
brasileiras e seus reflexos no índice da Basiléia: uma abordagem comparativa. Revista de Contabilidade e Organizaçóes, 16(6), 73 - 94, 2012.

AMARAL, L. Crises financeiras história e actualidade. Relaçóes Internacionais (R:I), n. 23 Lisboa set. 2009.

ARANTES, T. M., ROCHA, B. P. Eficiência dos bancos brasileiros e os impactos da crise financeira global de 2008. Associaçáo Nacional dos Centros de Pós-Graduaçáo em Economia (ANPEC), Brasília, DF, Brasil, 2012.

BERTOLO, L. A. A crise financeira, 2010. Disponível em: <http://www.bertolo.pro.br/ MatFin/HTML/crise_financeira.htm>. Acesso em: 31 maio 2016.

BEZERRA, M. M., CORREA, A. L., MENDONÇA A. R., CLEMENTINO M. L. Formação, sustentação ou implosão de uma bolha imobiliária? A dinâmica de preços no mercado de imóveis de Natal no período 2005-2010. Revista Economia e Sociedade, (47), $167-196,2013$.

BORTOLUZZI, D. A., BOLIGON, J. A. R., HOLLVEG, S. D. S., HOLLVEG, F. S. B. Aspectos do endividamento das famílias brasileiras no período de 2011-2014. Perspectiva, Erechim. v. 39, n.146, p. 111-123, junho/2015.

CAMPELLO, M., GRAHAM, J. R., HARVEY, C. R. The real effects of financial constraints: Evidence from a financial crisis. Journal of Financial Economics. 00(0), 470 $-487,2010$.

CAMPOS, K., SOUZA, M. M., MATOS, L. S. Impacto da Crise Econômica do Crédito nos Indicadores de Desempenho dos Maiores Bancos Brasileiros: Uma Análise entre os Anos de 2005 a 2012. Revista de Administraçáo, Contabilidade e Sustentabilidade, 5(2), $122-143,2015$.

CARVALHO, C. E. A crise internacional desafia o modelo brasileiro de abertura e liberalização. Revista Estudos Avançados, 23(66), 111 - 123, 2009.

CASTILHO, M. Impactos da Crise Econômica Internacional Sobre O Comércio Exterior Brasileiro. Crise Financeira Global: mudanças estruturais e impactos sobre os emergentes. Livro 2. Rio de Janeiro: IPEA, 2011.

DUCHIN, R., OZBAS, O., SENSOY, B. Costly external finance, corporate investment, and the subprime mortgage credit crisis. Journal of Financial Economics. 97, 418-435, 2010 .

FERRAZ, F. C. Crise financeira global: impactos na economia brasileira, política econômica e resultados. Dissertação de mestrado, Universidade Federal do Rio de Janeiro, Rio de Janeiro, RJ, Brasil, 2013. 
FRAGA, J.S., STRACHMAN, E. Crise financeira: O caso japonês. Revista Nova Economia, 23 (3). Belo Horizonte, Set - Dez 2013.

FREITAS, M. P. Os efeitos da crise global no Brasil: aversão ao risco e preferência pela liquidez no mercado de crédito. Revista Estudos Avançados, 23 (66), 2009.

GONÇALVES, R. S., TAVARES, A. L., XIMENES, P., SILVA R.M. Comportamento dos Dez Maiores Bancos Bras. Durante a Crise Subprime: uma Análise por Meio de Indicadores Contábeis. Revista de Educação e Pesquisa em Contabilidade, 6(2), 170 186, 2012.

IBGE. Cadastro geral de empregados e desempregados - CAGED. São Paulo, 2017. Disponível em: <http://www.ibge.gov.br/home/pesquisa/pesquisa_desemprego >. Acesso em: 25 fev. 2017.

MAKKONEN, H., POHJOLA, M., OLKKONEN, R., KOPONEN, A. Dynamic capabilities and firm performance in a financial crisis. Journal of Business Research, (67), $2707-2719,2014$.

MCKIBBIN, W., STOECKEL, A. The Global Financial Crisis: Causes and Consequences. International Economy Program, 2(9), 1 - 44, 2009.

MOLLER, H. D., VITAL, T. Os impactos da crise financeira global 2008/09 e da crise na área do euro desde 2010 sobre a balança comercial brasileira. Revista de Administraçáo, Contabilidade e Economia da FUNDACE Business School, 7, 1-19, 2013.

MONTEIRO, J. V. Um padrão de política pública na crise econômica mundial. Revista de Administração Pública, 42(6), 1237-1248, 2008.

MONTEIRO, J. V. Governança da crise econômica. Revista de Administraçáo Pública, 43(2), 521-529, 2009.

MONTEIRO, J. V. Percepçóes analíticas da crise econômica e racionalidade política.

Revista de Administraçáo Pública, 43(4), 979-991, 2009.

PEREIRA, J. M. A economia brasileira diante da crise mundial: fragilidade e perspectivas de crescimento. Revista Evidenciação Contábil \& Finanças, 2, 6-21, 2013.

PEREIRA, L. B. A crise financeira global e depois: um novo capitalismo? Revista Novos Estudos, $51-72,2010$.

RIBEIRO, F. F., SCHIOZER, R., F. Cessão de crédito e restrição de capital: um estudo com bancos brasileiros. Revista de Administraçáo de Empresas, 54(5), 521 - 536, 2014. 
RIBEIRO, F. R., LARA, R. O endividamento da classe trabalhadora no Brasil e o capitalismo manipulatório. Revista Serviço Social \& Sociedade. São Paulo, n. 126, p. 340-359, maio/ago. 2016.

SILVA, A., D., ALPERSTEDT, G., D. Mudança organizacional estratégica em um banco público: uma análise a partir da perda da conta movimento. Revista Administraçáo Pública, 47(4), 827-848, 2013.

SILVA, A. F., WEFFORT, E. F., FLORES, E. S., SILVA, G.P. Earnings management and economic crises in the brazilian capital market. Revista de Administraçáo de Empresas, 54(3), $268-283,2013$.

SILVA, F. J. F., NETO, F. A. F. Efeitos da crise financeira de 2008 sobre o desemprego nas regiōes metropolitanas brasileiras. Revista Nova Economia. 24 (2), Belo Horizonte MaiAgo 2014.

SINGER, P. A América Latina na crise mundial. Revista Estudos avançados, 23 (66), 91 $-102,2009$.

STREECK, W. The crises of democratic capitalism New Left Review, n. 71, 5-29, set.out. 2011.

TEIXEIRA, J. R., PINHEIRO, D. S., FERREIRA, P. F. Política econômica brasileira frente à crise mundial recente: uma análise baseada nas contribuiçóes de Kaldor. Revista do Serviço Público Brasília. 64 (2), 201 - 222, 2013.

VIEIRA, M. F. Por uma boa pesquisa (qualitativa) em administração. Pesquisa qualitativa em administração. 13-28, São Paulo: Editora FGV, 2004.

WAELTI, S. Financial crisis begets financial reform? The origin of the crisis matters. European Journal of Political Economy, 1-15, 2015. 